\title{
Assisted attenuation of a soil contaminated by diuron using hydroxypropyl- $\beta$-cyclodextrin and organic amendments
}

\author{
Marina Rubio-Bellido, Fernando Madrid, Esmeralda Morillo, Jaime
}

Villaverde $(\bowtie)$.

Instituto de Recursos Naturales y Agrobiología (IRNAS-CSIC), Apartado 1052, 41080

Sevilla, Spain

$(\bowtie)$ Corresponding author:

Jaime Villaverde

E-mail: jvillaverde@irnase.csic.es

Highlights

- HPBCD acts as an enhancer for diuron bioavailability

- Organic amendments (OAs) increase the rate of diuron mineralization

- OAs supplied specific diuron degrading microorganisms

- DOM from OAs acts as natural surfactant for diuron extraction

- HPBCD plus OAs application causes a positive synergy on diuron rate mineralisation 
32 Diuron desorption and mineralisation were studied on an amended and artificially contaminated soil. The amendments used comprised two different composted organic residues (i.e., sewage sludge mixed with pruning wastes (SS), and urban solid residues (USR), and two different solutions (with inorganic salts as the micronutrients) and hydroxypropyl- $\beta$-cyclodextrin (HPBCD). After applying micronutrients to activate the soil flora, $15.5 \%$ mineralisation could be reached after 150 days, indicating that the soil has a potential capacity to mineralise the herbicide through biostimulation-assisted attenuation. Diuron mineralisation was also improved when HPBCD solutions were applied. Indeed, the extent of herbicide mineralisation reached $29.7 \%$ with this application. Moreover, both the lag phase and the half-life time (DT $\left.{ }_{50}\right)$ were reduced to 33 and 1778 days, respectively, relative to the application of just microutrients (i.e., 39 and 6297 days, respectively). Organic amendments were also applied (i.e., USR and SS) on the contaminated soil: it was found that the diuron mineralisation rate was improved as the amendment concentration increased. The joint application of all treatments investigated at the best conditions tested was conducted to obtain the best diuron mineralisation results. The micronutrient amendment plus 4\% USR or SS amendment plus HPBCD solution (10-fold diuron initially spiked) caused an extent of diuron mineralisation 33.2 or $46.5 \%$, respectively.

51 Keywords: contaminated soil; mineralisation; diuron; hydroxypropyl- $\beta$-cyclodextrin; bioremediation; compost 
Phenylurea herbicides are widely used for the general control of non-crop areas and for selective pre- and post-emergence weed control on crops such as asparagus, cotton, maize or wheat; consequently, these herbicides constitute important environmental pollutants. Diuron is one such herbicides and it is the one that is most frequently

60 detected in groundwater (Di Bernardo Dantas et al., 2011; Giaccomazzi and Cochet, 2004). Moreover, this herbicide is included in the list of priority hazardous substances of the European Union (Malato et al., 2003), and is subjected to emission controls and quality standards to achieve "progressive reduction of 64 discharges, emissions and losses".

65

Diuron attenuation in the environment is primarily achieved through microbial

67 degradation processes (Villaverde et al., 2012). This mechanism yields the 68 corresponding aniline derivatives, for example 3,4-dichloroaniline (DCA), which 69 are considered to be more harmful to non-target organisms compared with the 70 parent herbicide. Although there are numerous studies on diuron dissipation in 71 soil-water systems, the complete diuron mineralisation has been described 72 relatively rarely in the literature (Sorensen et al., 2013; Villaverde et al., 2013a; 73 Villaverde et al., 2012; Bazot and Lebeau, 2009; Sorensen et al., 2008). 74 Mineralisation studies using ${ }^{14} \mathrm{C}$-ring-labelled diuron have demonstrated slow 75 mineralisation rates, with half-life values up to 4000 days in different soils 76 (Muhamad et al., 2013). At this time it is appropriate to provide the definition of 77 bioavailability and an interesting definition is that supplied by Katayama et al. (2010): "The amount of chemical available to be taken up or utilised by an 
organism/organisms in a defined time and environment". The most significant interaction between soils and xenobiotics that affects bioavailability is sorption, followed by aging and bound residue formation. The rate of uptake and subsequent degradation of chemicals by organisms is generally determined by the concentration of the chemicals in soil solution. It has been observed that the rate of 2011; Sun et al., 2012). For these reasons, the present investigations are focused on the development of different strategies for increasing the diuron bioavailability and therefore, mineralisation rate in soil-water systems. One of the strategies is the use of cyclodextrins (CDs), which are cyclic organic compounds that are obtained 90 through the enzymatic transformation of starch. These molecules posses a hydrophobic cavity and an exterior that is strongly hydrophilic. This peculiar structure allows organic molecules to be included in the cavity via non-covalent bonds to form inclusion complexes (Morillo et al., 2012). In previous studies, HPBCD solution at a very low concentration (i.e., only 10 times the diuron equimolar concentration in soil) as a bioavailability enhancer. This approach has

100 the effect of accelerating the passage of the diuron-desorbing fraction from the soil particle surface to the soil solution, thereby improving the accessibility of the endogenous microorganisms to the herbicide (Villaverde et al., 2012; Villaverde et al., 2013). Similarly, Villaverde et al. showed for the first time in 2012 that a 
104 cyclodextrin-based bioremediation technology coupled with the application of a specific bacterial diuron degrader consortium (bioaugmentation) was able to achieve almost a complete mineralisation of diuron in a soil-water system.

The other strategy is the use of compost obtained from different residues for

109 diuron soil remediation. Composts are rich sources of xenobiotics-degrading

110 microorganisms, which can degrade pollutants to innocuous compounds through

111 the process of mineralisation. However, the application of composts can also

112 decrease the bio-accessibility of chemicals, sequestering pollutants within the

113 organic matrix of the soil. Although recycling different organic wastes provides

114 benefits from an environmental point of view, to date, the use of composts has not

115 been widely applied as a method for bioremediation (Semple and Reid, 2001). The

116 success or failure of a compost remediation strategy depends on a number of

117 factors, the most important of which are the bioavailability and biodegradability of

118 the pollutant. The use of HPBCD has been demonstrated, as noted above, to

119 accelerate the mineralisation rate of persistent contaminants in water-soil systems,

120 which has enhanced their bioavailability. Therefore, the main objective of the

121 present work will be to test if the joint application of both strategies can improve

122 the mineralisation of diuron. These results will contribute to the discussion of

123 establishing a bioremediation technique as a practical choice based on chemical

124 bioavailability. 


\subsubsection{Chemicals}

131

132 Technical grade (98\%) diuron [N-(3,4-dichlorophenyl)-N,Ndimethylurea] was provided

133 by PRESMAR S.L. (Seville, Spain). Radiolabelled [ring-U- ${ }^{14}$ C]-diuron was purchased

134 from the Institute of Isotopes (Budapest, Hungary) with specific activity of $36 \mathrm{mCi}$

$135 \mathrm{mmol}^{-1}$, chemical purity of $99.9 \%$ and radiochemical purity of $100 \%$. The CD

136 employed was hydroxypropyl- $\beta$-CD (HPBCD) from Cyclolab (Budapest, Hungary) and

137 had a chemical purity of $97 \%$.

138

139 2.1.2. Soil

140

141 A loamy sandy agricultural soil from southwestern Spain with a pH of 8.7, $0.66 \%$

142 of organic matter (OM), $0.03 \mathrm{~g} \mathrm{~kg}^{-1}$ of dissolved organic matter (DOM) and a

143 particle size distribution of $\mathbf{7 4 \%}$ sand, $\mathbf{1 6 \%}$ silt, and $\mathbf{1 0 \%}$ clay was selected for this

144 study. The sample was taken from the horizon $(0-20 \mathrm{~cm})$, air-dried for $24 \mathrm{~h}$, and sieved

145 through $2 \mathrm{~mm}$ to remove stones and plant materials. The soil was frozen until its use.

146 The soil was analysed for particle size distribution (as measured using a Bouyoucos

147 densimeter), organic matter (as measured by $\mathrm{K}_{2} \mathrm{Cr}_{2} \mathrm{O}_{7}$ oxidation), $\mathrm{pH}$ (determined in the

148 1:2.5 soil/water extract), and total carbonate content (as measured using the manometric

149 method).

150

151

\subsubsection{Amendments}

152 
153 The micronutrients (trace elements, TEs) $\mathrm{CaSO}_{4} \cdot 2 \mathrm{H}_{2} \mathrm{O}, \quad \mathrm{ZnSO}_{4} \cdot 7 \mathrm{H}_{2} \mathrm{O}$, $\mathrm{Al}_{2}\left(\mathrm{SO}_{4}\right)_{3} \bullet 16 \mathrm{H}_{2} \mathrm{O}, \mathrm{NiCl}_{2} \bullet 6 \mathrm{H}_{2} \mathrm{O}, \mathrm{CoCl}_{2} \bullet 2 \mathrm{H}_{2} \mathrm{O}, \mathrm{KBr}, \mathrm{KCl}, \mathrm{MnCl}_{2} \bullet 4 \mathrm{H}_{2} \mathrm{O}, \mathrm{SnCl}_{2} \bullet 2 \mathrm{H}_{2} \mathrm{O}$ and $\mathrm{FeSO}_{4} \cdot 7 \mathrm{H}_{2} \mathrm{O}$ were used as the inorganic amendment (Fenlon et al., 2011) in the mineralisation experiments. Additionally, two composts were used as the organic amendments. The first, USR compost, was obtained from an experimental reactor that uses food residues at the University of Huelva (López et al., 2011). The second, a composted Biosolid (SS), was obtained from sewage sludge from a Wastewater Treatment Plant in Sevilla. The SS compost was mixed with pruning residues (15\%) to optimise the composting process and the final product. Both amendments are described in Table $1 . \mathrm{OM}$ was determined by dry combustion at $450^{\circ} \mathrm{C}$ (CEN, 1999), and the nitrogen (N) content was determined by distillation after Kjeldahl digestion. The total content of mineral nutrients and trace elements was determined after aqua regia digestion (CEN, 2002). The pH and the electric conductivity were determined in 1:5 (weight) compost/water extracts (USDA, 2001). Composts have a distinct nutrient content, which can help improving the microbial activity within the soils. The main difference between the residues is the organic matter content (i.e., it is much higher in the USR compost than in the SS compost because of the former's origin). The potentially toxic elements $(\mathrm{Cd}, \mathrm{Cu}$, $\mathrm{Pb}, \mathrm{Zn}$ ) of SS do not cause negative effects following its application to soil, as demonstrated by Madrid and Florido (2010), who did not observe increases in soil metal solubility using the same SS amendment, even at higher rates than used in

174 this assay. 
180 Assays to study the mineralisation of ${ }^{14} \mathrm{C}$-labelled diuron were performed in 181 respirometers to evaluate the potential soil attenuation and assisted-biodegradation 182 using different amendments, as described by Villaverde et al. (2013b). Briefly, the soil $183(10 \mathrm{~g})$ in each respirometer was spiked with diuron $\left(50 \mathrm{mg} \mathrm{kg}^{-1}\right)$ and a radioactivity of 184 approximately $450 \mathrm{~Bq}$ in a MMS medium $(50 \mathrm{~mL})$. A volume of $1 \mathrm{~mL}$ of micronutrients (TEs) solution was added to evaluate the effect of an inorganic amendment application on soil diuron mineralisation and the necessity of biostimulation

187 of the endogenous microflora. To determine the effect of CD application on soil diuron 188 mineralisation, a HPBCD solution, with a concentration 10 times the millimoles of 189 diuron concentration, was used as in Villaverde et al., 2012. To evaluate the effect of 190 the compost on the soil diuron mineralisation, the organic amendments were added to 191 the mineralization flasks at different concentrations: 0.5, 2 and 4\% (with respect to soil192 dry weight).

\subsubsection{Diuron extraction experiments}

196 Diuron extraction experiments were conducted to test the effect of micronutrients,

197 HPBCD and/or the composts studied on herbicide availability. For this purpose, 198 propylene centrifuge tubes containing $1 \mathrm{~g}$ of soil (previously spiked with $50 \mathrm{mg} \mathrm{kg}^{-1} \mathrm{of}$ 199 diuron) and $5 \mathrm{~mL}$ of the medium were spiked with micronutrients, HPBCD and/or 200 organic amendment at different concentrations while maintaining the same soil:solution 201 ratio as in the mineralisation assays). The tubes were agitated on an orbital shaker 
fibre membrane. The diuron concentration in the supernatant was determined in the filtrate with a Shimadzu HPLC equipped with a UV detector (wavelength 230 $\mathrm{nm})$ using the following conditions: mobile phase, acetonitrile/water (60:40); flow rate, $0.6 \mathrm{~mL} / \mathrm{min}$; temperature, $30{ }^{\circ} \mathrm{C}$; and chromatographic column, Kromasil C18 reverse 208 phase.

\subsubsection{Bacterial enumeration}

212 Enumeration of viable bacteria (potential diuron specific degraders) was achieved by

213 counting the colony forming unit counts/gram of soil or compost (CFUs g ${ }^{-1}$ ). Bacterial 214 enumeration was carried out using $1 \mathrm{~g}$ of soil or compost. The solids were whirl-mixed 215 for $30 \mathrm{~s}$ with $10 \mathrm{ml}$ of Ringer's solution, and then sonicated for $1 \mathrm{~min}$ and allowed to stand for 2 min. Aliquots $(100 \mu \mathrm{l})$ of these dilutions were applied on agar-agar plates

217 prepared from a R2a diluted medium (1:40), which is the herbicide content (40 $\mathrm{mg}^{-1}$ ) 218 that limits the carbon source for the soil endogenous flora and permits the selection of 219 diuron specific degraders. CFUs were counted after $48 \mathrm{~h}$.

\subsubsection{Model of mineralisation kinetics}

222

223 All the diuron mineralisation curves obtained were fit to the best kinetic model 224 employing an excel file provided by the FOCUS (2006) workgroup on degradation kinetics to facilitate kinetic analysis for parent compounds curves and the solver tool (Microsoft statistical package). 
228 The mineralisation curves were fitted to two kinetic models: a simple first-order model 229 (SFO) and a first-order sequential model (Hockey-Stick, HS). Parameters were 230 optimized adapting the recommendations by FOCUS (2006) to our mineralisation 231 processes, using the least-squares method with Microsoft Excel Solver and the 232 following equations:

$234[\mathrm{C}]_{\mathrm{t}}=[\mathrm{C}]_{0} \mathrm{e}^{-\mathrm{kt}}$

$[C]_{t}=[C]_{0} e^{-k 1 t b} e^{-k 2(t-t b)}$

237 where $[\mathrm{C}]_{\mathrm{t}}$ and $[\mathrm{C}]_{0}$ are the concentrations of mineralised diuron at time $\mathrm{t}$ and just after 238 spiking the soil, respectively $\left(\mathrm{mg} \mathrm{kg}^{-1}\right), \mathrm{k}$ is the rate constant of mineralisation $\left(\mathrm{day}^{-1}\right)$.

239 In the HS model, $\mathrm{k}_{1}$ and $\mathrm{k}_{2}$ are the rate constants of mineralisation for the fast and the 240 slow fractions, respectively, and tb is the time at which rate constant changes. These models have been selected for consideration based on their relative simplicity and their potential to better fit the measured dissipation kinetics datasets for diuron that appear to be monophasic or biphasic (Sharma and Rhoan, 2012; Beulke et al., 244 2005).

\section{Results and Discussion}

\subsection{Effect of composts on soil diuron mineralisation.}

250 The diuron soil mineralisation curves in the presence of the different amendments 251 applied at different concentrations are shown in Figure 1. All mineralisation curves fit 252 to a single first-order kinetic model (SFO). Diuron mineralisation without 
micronutrients amendment was negligible even in the presence of both composts (data not shown). The ability of soil to recover from chemical contamination is primarily dependent on the presence of a microbial community with the ability to remove it

(Caracciolo et al., 2013). The degradation of a chemical depends on abiotic and biotic 257 processes, but only the latter are responsible for its complete degradation 258 (mineralisation) and removal from the environment (Alexander, 1999). Although the selected soil was managed over several decades with different herbicides, and its endogenous flora would potentially be able to biodegrade these type of molecules, the experimental results showed that these microorganisms require different essential micronutrients. However, the addition of inorganic micronutrients (TEs) was not sufficient to cause a significant increase in the mineralisation rate of the herbicide, and only a $15.5 \%$ extent of mineralisation could be reached (DT D0: 6297 days, Table 2).

Diuron mineralisation curves after compost application are also shown in Figure 1. $\mathrm{DT}_{50}$ was drastically reduced as the percentage of compost application was increased (Table 2), reaching a value of approximately 240 days, which is 26 times lower than that obtained with only TEs when 4\% SS compost was added. Moreover, the extent of mineralisation reached approximately $33 \%$ for both composts with doses of $4 \%$.

271 Ellegaard-Jensen et al. (2013) showed that degradation of diuron was faster in carbon-

272 and nitrogen-rich media, whereas suboptimal nutrient levels restricted degradation. In 273 this way, enhanced bioremediation may be achieved adjusting the nutrient content of 274 contaminated soil (Tejada et al., 2010; Teng et al., 2010).

276 Adding exogenous organic matter improves the biological, physical and chemical soil 277 properties and its fertility (Thevenot et al., 2008). These changes also influence 
278 biodegradation, retention and the transport of pesticides in soil (López-Piñero et al.,

279 2013; Herrero-Hernández et al., 2011; Romero et al., 2010). The increase of organic 280 matter in soil generally results in an increase in the sorption of hydrophobic pesticides

281 (Wauchope et al., 2002). However, this is not the only soil property associated with 282 hydrophobic pesticide sorption (Morillo et al., 2004). Villaverde et al. (2013b) and 283 Undabeytia et al. (2011) showed that the diuron sorption mechanism is related to some 284 other soil properties in addition to the OC content, such as the content of clay minerals.

Most published works have described a retention-sequestration effect on organic contaminants that gives rise to a decrease in their availability (Puglisi et al., 2007; Tejada et al., 2011). In contrast, Barriuso et al. (1997) showed that although the addition of compost generally favoured the stabilisation of herbicide residues, this effect depends on the type of organic amendment. Exogenous and endogenous dissolved organic matter (DOM) may influence the transport of pesticides, through the formation of DOM-pesticide complexes and/or the competition between DOM and pesticides for the adsorption sites in the soil (Williams et al., 2002). Thevenot et al. (2009) performed

294 diuron leaching experiments using columns to investigate DOM-diuron interactions and the possible co-transport of diuron and DOM using four different organic amendments. These interactions appear to be related to the aromatic and aliphatic content of the DOM, which suggests the formation of hydrogen and other non-covalent bonds.

298 Wischmann and Steinhart (1997) showed that supplementation of contaminated soils 299 with compost materials could enhance PAHs biodegradation.

301 Diuron extraction experiments (Figure 2) were performed to determine the effect of 302 both composts on diuron availability. The soil:solution relation used was the same as 
303 that used in the mineralisation assays. The DOM concentration of the two composts

304 were very different, i.e., 0.7 and $0.1 \mathrm{~g} \mathrm{~kg}^{-1}$ for USR and SS, respectively (Table 1).

305 However, this difference did not influence the amount of diuron extracted from soil

306 (i.e., $4.45 \%$ for USR and $4.47 \%$ for SS, fig. 2) when using $4 \%$ of each compost. These

307 amounts are 4.6 times higher than that obtained when only micronutrients were applied

308 in the soil $(0.96 \%$, Figure 2$)$, and this increase is because of the formation of DOM-

309 diuron complexes as observed previously (Thevenot et al., 2008; Cox et al., 2004;

310 Imache et al., 2012). Although SS and USR possess different DOM concentrations

311 (0.28 and $0.04 \mathrm{mg} \mathrm{DOM} / \mathrm{g}$ of soil, respectively), a similar diuron extraction was

312 obtained, indicating that the quality of DOM supplied plays also an important role in

313 diuron availability.

314

315 The formation of DOM-diuron complexes in solution does not fully explain the

316 significant decrease of $\mathrm{DT}_{50}$ for diuron mineralisation, which was divided by 26 after

317 the application of $4 \%$ of both composts (Table 2). In addition to DOM, another

318 explanation would be the nutrients supplied by the composts, particularly organic

319 labile nutrients from the USR and SS organic matter (Table 1), which would act as

320 a carbon source for the soil endogenous flora. However, the amounts of available

321 micronutrients such as $\mathrm{K}, \mathrm{Fe}, \mathrm{Mn}, \mathrm{Zn}$ or Ni supplied as biostimulants by the

322 composts are likely to be in low concentrations, which would explain why

323 significant mineralisation was not observed when only SS and USR were supplied

324 to the soil in the absence of TEs. 
However, the application of compost can act as a soil ameliorant capable of improving

328 the contaminated soil environment by introducing microbial degradative activity

329 (Semple et al., 2001). Composts are capable of sustaining diverse populations of

330 microorganisms with the potential to degrade a variety of aromatic pollutants. In our

331 case, potential diuron specific degrading CFUs were determined, both in the selected

332 soil and in composts (Table 1). We noted the presence of a high number of CFUs in

333 the composts used, which were multiplied by 28 and 82 in the soil in the presence

334 of USR and SS, respectively.

3.2. Effect of HPBCD on soil diuron mineralisation.

338 The diuron soil mineralisation curves in the presence of HPBCD are shown in Figure 3a 339 and 3b. Unlike the previously discussed mineralisation curves (Table 2), degradation 340 could not always be described by single first-order kinetics, as recommended by 341 FOCUS (2006). Many simulation models accept only first-order half-life as an

342 input degradation parameter; however, in recent years attempts have been made

343 to incorporate degradation parameters obtained through models other than first-

344 order kinetic (Sarmah et al., 2009). Using the SFO model for all types of decay

345 patterns could lead to the under- or overestimation of the dissipation endpoints

346 when the deviation from first-order is significant. Srinivasan et al., (2014)

347 concluded that the dissipation times for the antibiotic sulfamethoxazole in soil

348 demonstrated that the non-linear biphasic models improved the goodness-of-fit

349 parameters for all datasets of the SFO model. Further, Sarmah and Rohan (2011)

350 observed that the biexponential model could describe the dissipation kinetics of 4-

$351 \quad n$-nonylphenol and bisphenol-A in groundwater-aquifer material slurry. 
352 The diuron mineralisation curves in the presence of a HPBCD solution were fit to a

353 hockey-stick first-order kinetic model (HS), which consists of two sequential first-order 354 curves, where a fast initial decrease in pesticide concentrations is followed by a slower

355 decline. This is usually referred to as a bi-phasic pattern of pesticide degradation. The 356 pesticide concentration initially declines according to first-order kinetics with a rate 357 constant $\mathrm{k}_{1}$. However, at a certain point in time (i.e., the breakpoint, tb), the rate 358 constant changes to a different value $\mathrm{k}_{2}$.

359

360 As observed in Table 2, the diuron mineralisation rate $\mathrm{k}_{1}$ was multiplied by 5 relative to 361 the case when only TEs were applied to the soil. In a previous work, the ability of 362 HPBCD to extract the diuron soil bioaccessible fraction was confirmed by Villaverde et 363 al., (2013b). HPBCD can extract the entire bioavailable diuron fraction, resulting 364 in its rapid mineralisation, as shown in the first part of the mineralisation curve (Figure 3). Here, approximately $30 \%$ diuron was mineralised in the first 40 days after HPBCD was applied. The recalcitrant or strongly sorbed herbicide fraction is

367 considered unimportant from a toxicological and environmental point of view

368 (Mahmoudi et al., 2013). Semple et al. (2007) asserted that HPBCD extraction is able to assess the bioaccessible fraction in a soil-water system of low molecular weight polycyclic aromatic hydrocarbons (PAHs). Additionally, CD extractions were capable

371 of predicting the microbial degradation of organic contaminants using laboratory-spiked 372 soils.

374 The role of HPBCD as a diuron bioavailability enhancer and, as a consequence, a 375 mineralisation increaser could be due to two different effects: a) the formation of an 376 inclusion complex in solution that may increase diuron solubility and/or b) HPBCD 
may be used as a carbon source by the indigenous microorganisms of the soil and promote their growth. This latter effect has been demonstrated to be invalid, because various tests (data not shown) have shown that the number of specific diuron degraders CFUs did not increase in the presence of HPBCD, suggesting that the bacterial consortium tested does not use HPBCD as a carbon source.

383 However, the first effect has been observed in previous work (Villaverde et al., 2012), where a significant increase in diuron hydrosolubility in the presence of HPBCD was noted. These diuron solubility studies in the aqueous phase in the presence of different CDs showed that the best complexation parameters for the formation of CD-diuron water-soluble inclusion complexes were obtained in the case of HPBCD. CDs are

388 considered novel hosts for the complexation of hydrophobic compounds in the 389 environment, including PAHs and pesticides and even some emerging contaminants such as alkylphenols (Morillo et al., 2014; Villaverde et al., 2014; Sánchez-Trujillo et al., 2013). Consequently, the use of CDs can address some of the largest problems

392 facing chemistry, such as the increase of pollution in the environment (Albelda et al., 393 2012). CDs are considered non-toxic, biodegradable (Fenyvesi et al., 2005) and environmentally friendly molecules (Badr et al., 2004; Gould and Scott, 2005). The role of HPBCD to act as an enhancer of diuron bioavailability has been shown in previous desorption studies of organic contaminants in different soils (Villaverde et al., 2013a;

397 Sánchez-Trujillo et al., 2013; Villaverde et al., 2005; Pérez-Martínez et al., 2000) and 398 soil colloidal components (Villaverde et al., 2013b). In the present paper it has also been 399 demonstrated through extraction experiments that the presence of HPBCD causes an 400 increase in the diuron desorbing fraction, reaching $14.7 \%$ of diuron desorbed relative to 401 the amount desorbed in the absence of $\operatorname{HPBCD}(0.96 \%$, Figure 2$)$. 
403

404 Based on the results obtained for accelerating diuron mineralisation following the application of different composts on diuron contaminated soil, the joint application of each amendment at the best ratio (i.e., 4\% for SS and USR) and HPBCD was conducted. The corresponding diuron mineralisation curves are shown in Figures $3 \mathrm{a}$ and 3b. In both cases, the curves best fit to a hockey-stick first-order kinetic model with a drastic increase for samples including TEs, in the diuron mineralisation rate in the first part of the curve $\left(\mathrm{k}_{1}=2.0 \times 10^{-2}\right.$ and $2.5 \times 10^{-2} \mathrm{~d}^{-1}$ for SS- and USR-HPBCD, 411 respectively).

413 The application of SS-HPBCD led to a $\mathrm{DT}_{50}$ of only 174 days, which is a 36-fold 414 reduction in time to mineralise $50 \%$ of the diuron initially applied versus the application of just TEs. Additionally, the joint application of SS-HPBCD achieved an important enhancement in the rate of mineralisation, reaching $46.5 \%$ of the herbicide mineralised

417 (Table 2). From these latter results, it seems that the diuron bioavailable fraction was

418 increased, because a higher percentage of the herbicide was mineralised than when only

419 HPBCD was applied, which could be due to the combined effect of the natural 420 surfactant, DOM, the formation of an inclusion complex between HPBCD and diuron and the supplied of the specific diuron degraders. Yu et al. (2011) observed a similar combined effect of DOM and biosurfactants on the desorption of PAHs in a soil-water system, concluding that the synergistic effect caused by increasing the potential hydrophobic surface of the complex DOM-HPBCD was able to extract organic compounds (Nkambule et al., 2009). 
427 It is also notable that the SS-HPBCD treatment elicited a larger effect on diuron

428 mineralisation than did the USR-HPBCD treatment (i.e., DT $_{50}: 174$ versus 1606 days;

429 lag phase: 11 versus 16 days, for SS- and USR-HPBCD, respectively). In Figure 2

430 diuron extraction in the presence of HPBCD and SS compost was much higher (50.7\%)

431 than that of the system with HPBCD or compost individually (14.7 and $4.47 \%$,

432 respectively). In the case of the USR-HPBCD application, this effect was not as evident,

433 although the combined effect was also higher than the isolated applications (34\%). The

434 fact that the USR compost possesses an OM content $>3.5$ times higher than that of the

435 SS could be the reason for the lower increase in both the extraction and the

436 mineralisation of diuron in the presence of HPBCD. For this reason, the USR compost

437 possesses a higher diuron adsorption than the SS compost, and hence, diuron extraction

438 this will be lower in the soil amended with the compost with the higher OM content,

439 which in this case is (USR).

440

441

\section{Conclusions}

442

443 Diuron mineralisation was possible only after the application of the essential nutrients for soil microorganisms (TEs). The improvement in the rate of diuron mineralisation following the application of compost on soil was mainly due to: i) the supply of specific diuron degraders present in the organic amendments; ii) the

447 presence of labile organic nutrients from compost OM used as a carbon source by 448 soil microorganisms; and iii) DOM acting as a natural extractant that increases the concentration of diuron in the soil solution. The joint application of all treatments investigated at the best conditions tested was conducted to obtain the best diuron mineralisation results. The use of HPBCD has been demonstrated to accelerate the 
452 mineralisation rate because improvement of diuron bioavailability in water-soil systems. The joint application of all treatments investigated at the best conditions

454 tested was conducted to obtain the best diuron mineralisation results. The micronutrient amendment plus 4\% USR or SS amendment plus HPBCD solution (10-fold diuron initially spiked) caused an extent of diuron mineralisation 33.2 or $46.5 \%$, respectively.

458

It is important to highlight that the soil bioremediation strategy proposed in this work presents a feasible remediation technology from both an environmental and economic point of view. Indeed, a significant increase in the diuron mineralisation rate was achieved, which makes this bioremediation technique a viable option.

Acknowledgements

Marina Rubio thanks the Spanish Research Council (CSIC) for her Predoctoral Research grant (JAE-Pre). The authors are indebted to Presmar S.L. for providing the technical diuron. This work was supported by the Spanish Ministry of Science and Innovation (co-funded by the Fondo Europeo de Desarrollo Regional, FEDER) under the research project CTM2009-07335 and Junta de Andalucía (RNM 894). 
482 Alexander M. Biodegradation and bioremediation, second edition. Academic Press 4831999.

484 Albelda M, Frías JC, García-España E, Schneider HJ. Supramolecular complexation for 485 environmental control. Chem Soc Rev 2012;41:3859-77.

486 Badr T, Hanna K, Brauer C. Enhanced solubilization and removal of naphthalene and 487 phenanthrene by cyclodextrins from two contaminated soils. J Hazard Mat 2004;21548823.

489 Barriuso E, Houot S, Serra-Wittling C. Influence of compost addition to soil on the 490 behavior of herbicide. Pest Sci 1997;49:65-75.

491 Bazot S, Lebeau T. Effect of immobilization of bacterial consortium on diuron 492 dissipation and community dynamics. Bioresour Technol 2009;100:4257-61.

493 Caracciolo AB, Bottoni P, Grenni P. Microcosm studies to evaluate microbial potential 494 to degrade pollutants in soil and water ecosystems. Microchemical 2013;107:126-130.

495 Cox L, Fernandes MC, Zsolnay A, Hermosín MC, Cornejo J. Changes in dissolved 496 organic carbon of soil amendments with aging: Effect on pesticide adsorption 497 behaviour. J Agric Food Chem 2004;52:5635-42.

498 Di Bernardo Dantas A, Paschoalato CRF, Martínez MS, Ballejo RR, Di Bernardo L. 499 Removal of diuron and hexazinone from guarany aqyuifer groundwater. Braz J Chem $500 \quad$ Eng 2011;28:415-424.

501 Dou J, Lia S, Chenga L, Dinga A, Liub X, Yunc Y. The Enhancement of Naphthalene 502 Degradation in Soil by Hydroxypropyl- $\beta$-cyclodextrin. Proc Environ Sci 2011;10:2650331.

504 El Imache A, Dousset S, Satrallah A, Dahchour A. Effects of sewage sludge 505 amendments on pesticide sorption and leaching through undisturbed Mediterranean 506 soils. J Environ Sci Health Part B 2012;47:161-67.

507 Elleggaard-Jensen L, Aamand J, Kragelund BB, Johnsen AH, Rosendahl S. Strains of 508 the soil fungus Mortierella show different degradation potentials for the phenylurea 509 herbicide diuron. Biodegradation 2013;24:765-74.

510 Fenlon KA, Andreou K, Jones KC, Semple KT. The extractability and mineralisation of 511 cypermethrin aged in four UK soils. Chemosphere 2011;82:187-192.

512 Fenyvesi E, Gruiz K, Verstichel S, de Wilde B, Leitgib L, Csabai K. Biodegradation of 513 cyclodextrins in soil. Chemosphere 2005;60:1001-08.

514 FOCUS. Guidance Document on Estimating Persistence and Degradation Kinetics from 515 Environmental Fate Studies on Pesticides in EU Registration" Report of the FOCUS 516 Work Group on Degradation Kinetics, EC Document Reference Sanco/10058/2005 517 version $2.02006 ; 434$ pp.

518 Giaccomazzi S, Cochet N. Environmental impact of diuron transformation: a review. 519 Chemosphere 2004;56:1021-32.

520 Gould S, Scott RC. 2-Hydroxypropyl- $\beta$-cyclodextrin (HP- $\beta$-CD): A toxicology review. 521 Food Chem Toxicol 2005;43:1451-59. 
Gruiz K, Feigl V, Hajdu CS, Tolner M. Environmental toxicity testing of contaminated soil base don microcalorimetry. Environ Toxicol 2010;25:479-486.

524 Herrero-Hernández E, Andrades MS, Rodríguez-Cruz MS, Sánchez-Martín MJ. Effect 525 of spent mushroom substrate applied to vineyard soil on the behabiour of copper-based 526 fungicide residues. J Environ Manag 2011;92:1849-57.

527 Katayama A, Bhula G, Carazo E, Felsot A, Hamilton D. Bioavailability of xenobiotics 528 in the soil environment. Rev Environ Cont Toxicol 2010;203-08.

López R, Cabeza IO, Giráldez I, Díaz MJ. Biofiltration of composting gases using 530 different municipal solid waste-pruning residue composts: Monitoring by using an electronic nose. Biores Technol 2011;102:7984-93.

532 López-Piñeiro A, Peña D, Albarrán A, Becerra D, Sánchez-Llerena J. Sorption, leaching and persistence of metribuzin in Mediterranean soils amended with olive mill waste of different degrees of organic matter maturity. J Environ Manag 2013;122:76-84.

Mahmoudi N, Slater FS, Juhasz AL. Assesing limitations for PAH biodegradation in long-term contaminated soils using bioaccessibility assays. Wat Air Soil Pollut. 2013;224:1411-16.

538 Malato S, Cáceres J, Fernández-Alba AR, Piedra L, Hernando MD, Agüera A, Vial I. 539 Photocatalytic treatment of diuron by solar photocatalysis: evaluation of main 540 intermediates and toxicity. Environ Sci Technol 2003;37:2516-24.

541 Pérez-Martínez JI, Ginés JM, Morillo E, González-Rodríguez ML, Moyano JR. 542 Improvement of the desorption of the pesticide 2,4-D via complexation with HP- $\beta$ 543 cyclodextrin. Pest Manag Sci 2000;56:425-430.

544 Morillo E, Undabeytia T, Cabrera A, Villaverde J, Maqueda C. Effect of soil type on 545 adsorption-desorption, mobility, and activity of the herbicide norflurazon. J Agric Food 546 Chem 2004;52:884-90.

547 Morillo E, Sánchez-Trujillo MA, Moyano JM, Villaverde, J, Gómez-Pantoja E, Pérez548 Martínez JI. Enhanced solubilisation of six PAHs by three synthetic cyclodextrins for remediation applications: molecular modeling of the inclusion complexes. Plos One 2012;7:e44137.

555 Muhamad H, Ramli MI, Zakaria Z, Sahid I. The fate of diuron in soil in a malaysian oil 556 palm plantation. J Oil Palm Res 2013;25:149-58.

557 Nkambule TI, Krause RW, Mamba BB, Haarhoff J. Removal of natural organic matter 558 from water using ion-exchange resins and cyclodextrin polyurethanes. Phy Chem Earth 559 2009;34:812-18.

560 Puglisi E, Cappa F, Fragoulis G, Trevisan M, Del Re AAM. Bioavailability and 561 degradation of phenanthrene in compost amended soils. Chemosphere 2007;67:548- 56.

562 Romero E, Fernánde-Bayo J, Castillo Díaz JM, Nogales R. Enzyme activities and 563 diuron persistence in soil amended with vermicompost derived from spent grape marc and treated with urea. Appl Soil Ecol 2010;44:198-04. 
Sánchez-Trujillo MA, Morillo E, Villaverde J, Lacorte S. Comparative effects of 566 several cyclodextrins on the extraction of PAHs from an aged contaminated soil. 567 Environ Pollut 2013;178:52-58.

568 Sarmah AK, Close ME. Modelling the dissipation kinetics of six commonly used 569 pesticides in two contrasting soils of New Zealand. J Environ Sci Health Part B $570 \quad 2009 ; 44: 507-517$.

571 Semple KT, Reid BJ, Fermor TR. Impact of composting strategies on the treatment of 572 soils contaminated with organic pollutants. Environ Poll 2001;112:269-83.

573 Semple KT, Doick LJ, Wick LY, Harms H. Microbial interactions with organic 574 cantaminants in soil: Definitions, processes and measurement. Environ Pollut 575 2007;150:166-76.

576 Sorensen SR, Albers CN, Aamand J. Rapid Mineralization of the Phenylurea Herbicide 577 Diuron by Variovorax sp. Strain SRS16 in Pure Culture and within a Two-Member 578 Consortium. Appl Environ Microbiol 2008;2332-40.

579 Sorensen SR, Juhler RK, Aamand J. Degradation and mineralisation of diuron by 580 Sphingomonas sp. SRS2 and its potential for remediating at a realistic $\mu \mathrm{g}-1$ diuron 581 concentration. Pest Manag Sci 2013;69:1239-44.

582 Sun M, Luo Y, Christie P, Jia Z, Li Z, Teng Y. Methyl- $\beta$-cyclodextrin enhanced 583 biodegradation of polycyclic aromatic hydrocarbons and associated microbial activity in 584 contaminated soil. J Environ Sci 2012;24:926-33.

585 Tejada M, García-Martínez AM, Gómez I, Parrado J. Application of MCPA herbicide 586 on soils amended with biostimulants: Short-time effects on soil biological properties. 587 Chemosphere 2010;80:1088-94.

588 Tejada M, Benítez C. Organic amendment based on vermicompost and compost: 589 differences on soil properties and maize yield. Waste Manag Res 2011;29:1185-96.

590 Teng Y, Luo Y, Ping L, Zou D, Li Z, Christie P. Effects of soil amendment with 591 different carbon sources and other factor son the bioremediation of an aged PAH592 contaminated soil. Biodegradation 2010;21:167-78.

593 Thevenot M, Dousset S, Rousseaux S, Andreux F. Influence of organic amendments on 594 diuron leaching through an acidic and a calcareous vineyard soil undistrurbed 595 lysimeters. Environ Pollut 2008;153:148-56.

596 Thevenot M, Dousset S, Hertkorn N, Schmitt-Kopplin P, Andreux F. Interactions of 597 diuron with dissolved organic matter from organic amendments. Sci Total Environ 598 2009; 407; 4297-02.

599 Undabeytia T, Recio E, Maqueda C, Sánchez-Verdejo T, Balek V. Slow diuron release 600 formulations based on clay-phosphatidylcholine complexes. Pest Manag Sci $601 \quad 2011 ; 67: 271-78$.

602 Villaverde J, Morillo E, Pérez-Martínez JI, Ginés JM, Maqueda C. Preparation and 603 Characterization of Inclusion Complex of Norflurazon and $\beta$-Cyclodextrin To Improve 604 Herbicide Formulations. J Agric Food Chem 2004;52:864-69.

605 Villaverde J, Maqueda C, Morillo E. Improvement of the Desorption of the 606 Herbicide Norflurazon from Soils via Complexation with $\boldsymbol{\beta}$-Cyclodextrin. J Agric 607 Food Chem 2005;53:5366-5372. 
608 Villaverde J, Posada-Baquero R, Rubio-Bellido M, Laiz L, Saiz-Jimenez C, Sánchez609 Trujillo M.A, Morillo E. Enhanced mineralization of diuron using a cyclodextrin-based 610 bioremediation technology. J Agric Food Chem 2012;60:9941-47.

611 Villaverde J, Posada-Baquero R, Rubio-Bellido M, Morillo E. Effect of hydroxypropyl$612 \beta$-cyclodextrin on diuron desorption and mineralisation in soils. $\mathrm{J}$ Soil Sed 613 2013a;13:1075-83.

614 Villaverde J, Rubio-Bellido M, Posada-Baquero R, Madrid F, Morillo E. 615 Hydroxypropil- $\beta$-cyclodextrin-based extraction for diuron bioaccessibility in an 616 artificially contaminated soil. Int J Environ Anal Chem 2013b;93:1620-27.

617 Wauchope RD, Yeh S, Linders JB, Kloskawski R, Tanaka K, Rubin B, Katayama A, 618 Kördel W, Gerstl Z, Lane M, Unsworth J. Pesticide sorption parameters : theory, 619 measurements, uses, limitations and reliability. Pest Manag Sci 2002;58:419-55.

620 Williams CF, Letey J, Farmer WJ. Molecular weight of dissolved organic matter621 napropamide complex transported through soil columns. J Environ Qual 2002;31:61962227.

623 Wischmann $\mathrm{H}$, Steinhart $\mathrm{H}$. The formation of PAH oxidation products in soils and 624 soil/compost mixtures. Chemosphere 1997;35:1681-98.

$625 \mathrm{Yu} \mathrm{H}$, Huang GH, An CJ, Wei J. Combined effects of DOM extracted from site 626 soil/compost and biosurfactant on the sorption and desorption of PAHs in a soil-water 627 system. J Hazard Mat 2011;190:883-90.

628 Zhu H, Aitken M. Surfactant-Enhanced Desorption and Biodegradation of Polycyclic 629 Aromatic Hydrocarbons in Contaminated Soil. Environ Sci Technol 2010;44:7260-65.

630

631

632

633

634

635

636

637

638

639

640

641

642

643

644

645

646 
649 Figure 1. Mineralisation of ${ }^{14} \mathrm{C}$-labeled diuron in soil in the presence of micronutrients

650 ( ) and after the addition of a) SS compost and b) USR compost applied at different 651 concentrations: measured residues $4 \%(\boldsymbol{\Delta}), 2 \%(\boldsymbol{\square}), 0.5 \%(\checkmark)$, with the fit for SFO or

652

653

654

655

656

657

658

659

660

661

662

663

664

665

666

667

668

669

670

671

672

673

674

675

676

677

678

679

680

681

682

683

684

685

686

687

688
Figure 2. Extracted diuron in the presence of micronutrients (TEs), HPBCD, USR and SS compost, $4 \%$ and compost + HPBCD.

Figure 3. Mineralised diuron in soil in the presence of $4 \%$ SS compost (a) and USR compost (b). The different treatments are only compost $(\boldsymbol{\Delta})$, only HPBCD $(\boldsymbol{\nabla})$ and in combination: composts + HPBCD (ם), with the fit for SFO or HS model (solid line).

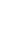




\section{Graphical abstract}

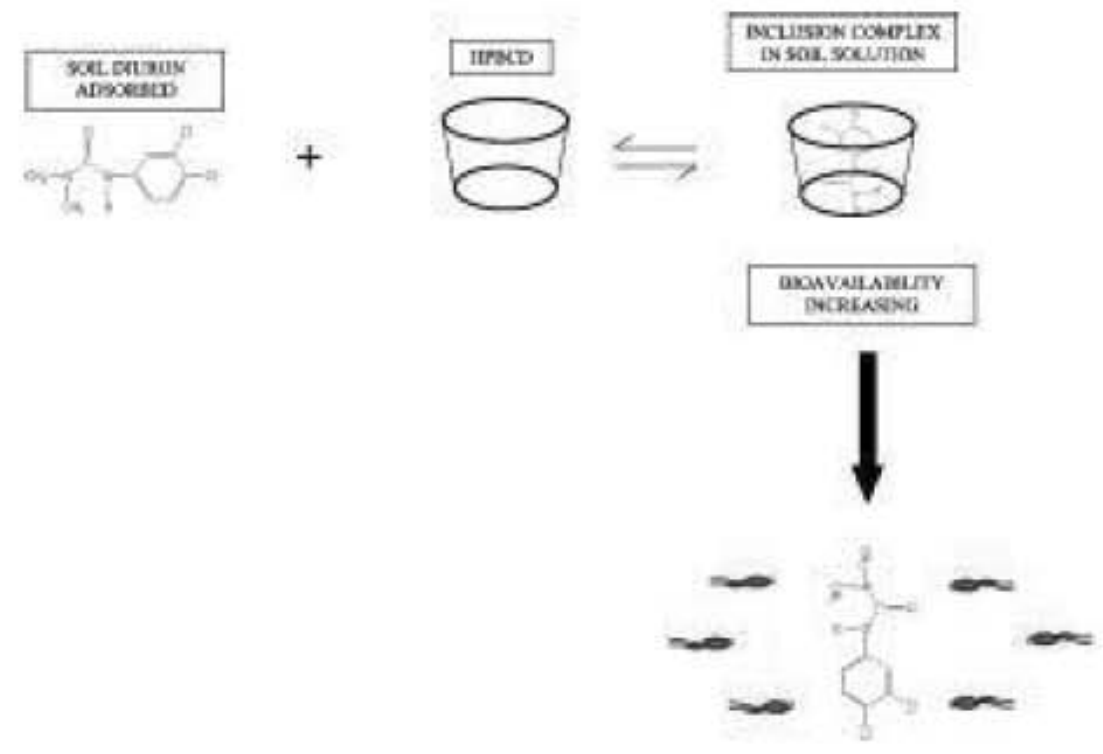

\section{Figura 1.}
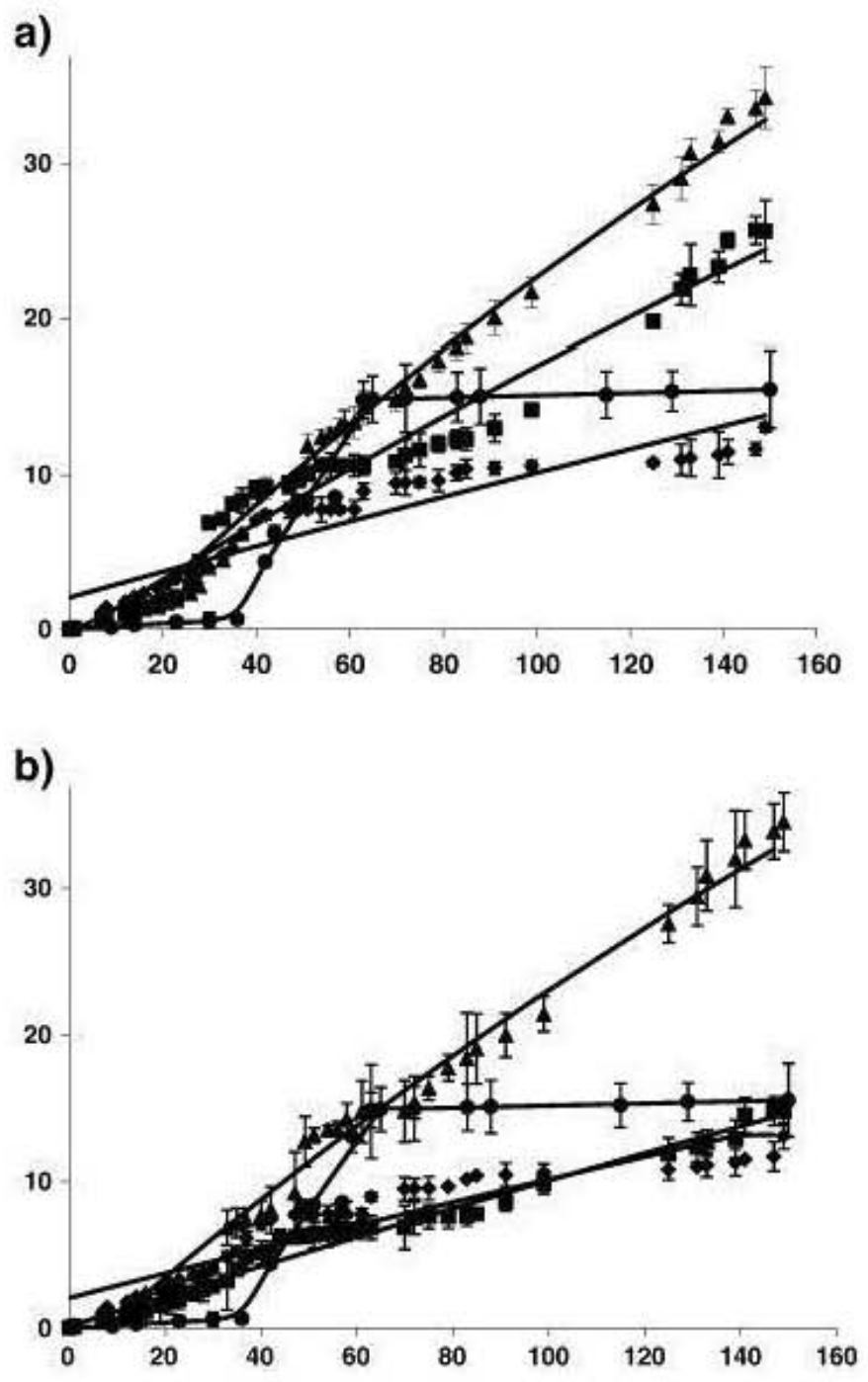

Mineralisation of ${ }^{14} \mathrm{C}$-labelled diuron in soil in the presence of micronutrients $(\bullet)$ and after the addition of a) SS compost and b) USR compost applied at different concentrations: measured residues $4 \%(\boldsymbol{\Delta}), 2 \%(\boldsymbol{\square}), 0.5 \%(\bullet)$, with the fit for SFO or HS model (solid line). 
Figura 2.

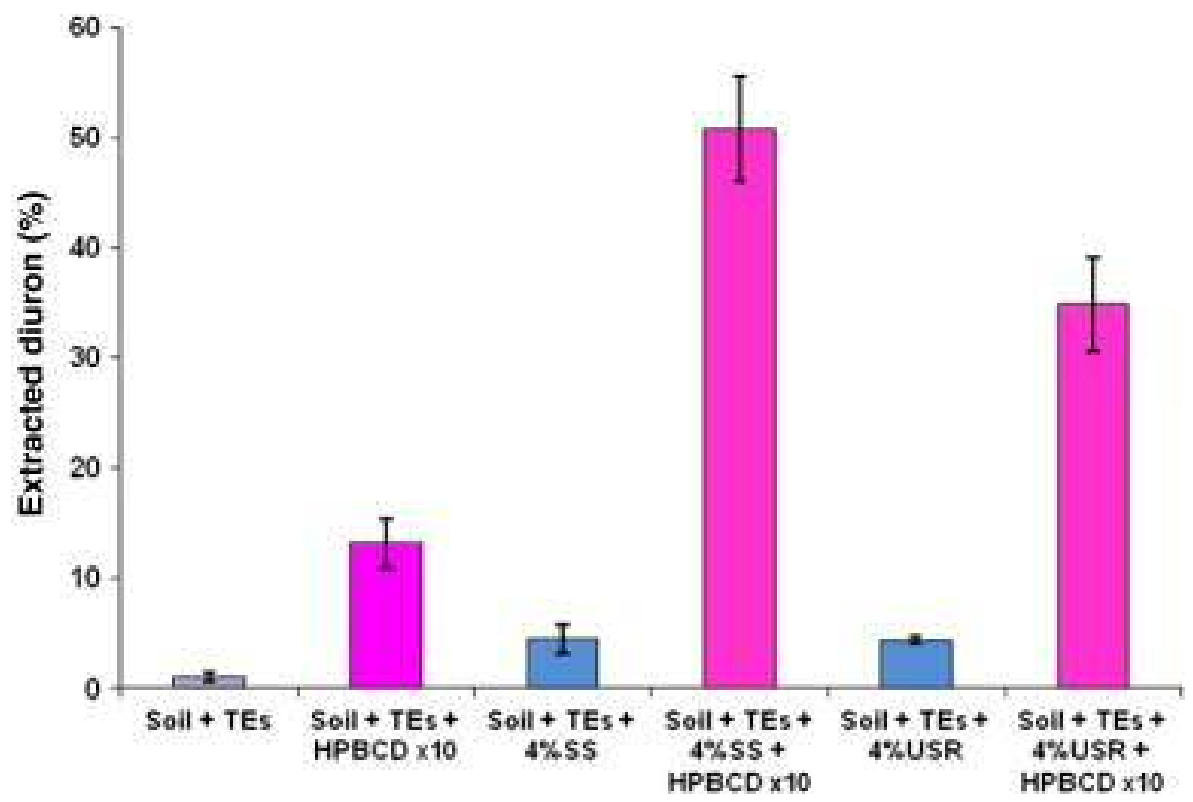

Extracted diuron in the presence of micronutrients (TEs), HPBCD, USR and SS compost (4\%), and compost + HPBCD.

\section{Figura 3.}

a)
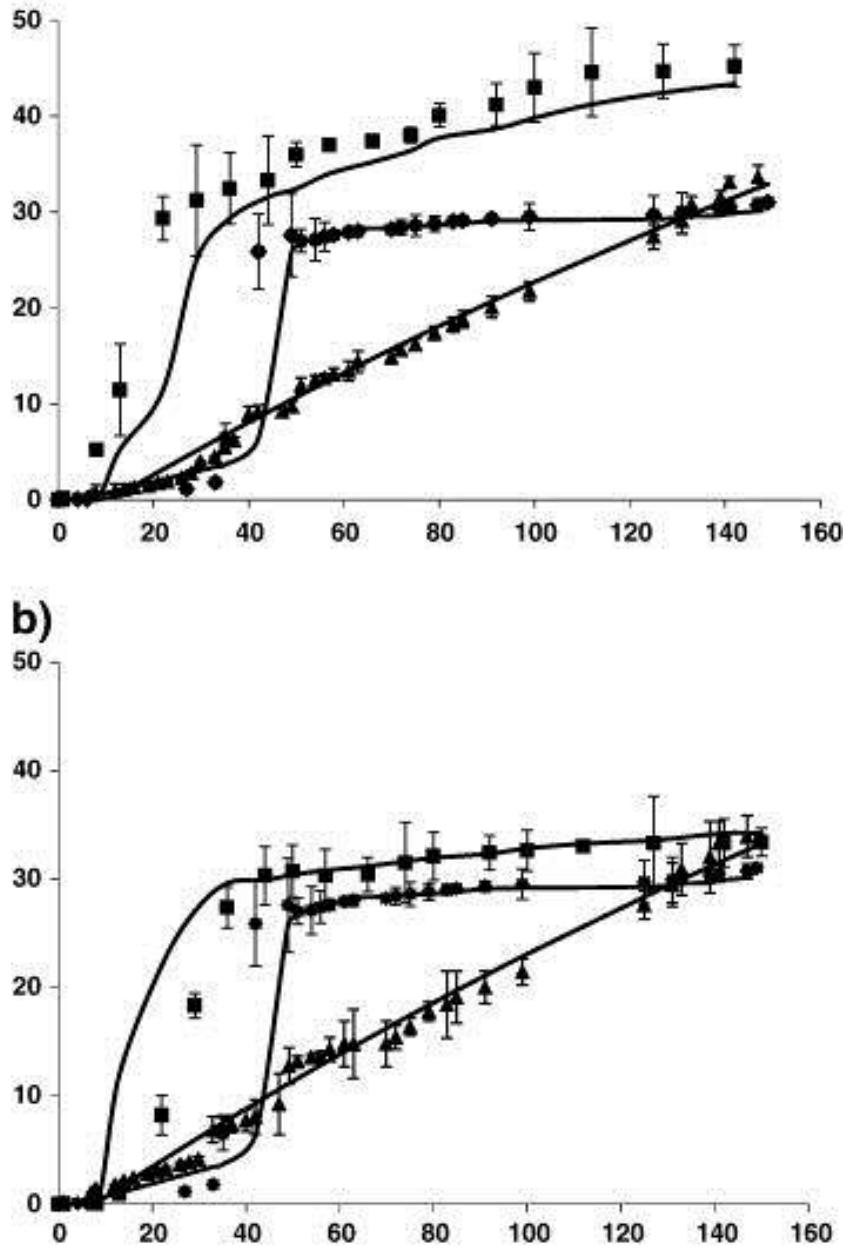

Mineralised diuron in soil in the presence of $4 \%$ SS compost (a) and USR compost (b). The different treatments are only compost $(\mathbf{\Delta})$, only HPBCD $(\bullet)$ and in combination: composts + HPBCD $(\mathbf{\square})$, with the fit for SFO or HS model (solid line). 
Table 1. Main properties of the composts used.

\begin{tabular}{|c|c|c|}
\hline Properties & USR & SS \\
\hline Organic matter (\%) & 79 & 22 \\
\hline $\mathrm{pH}$ & 6.7 & 6.4 \\
\hline Electrical conductivity $\left(\mathrm{dS} \mathrm{m}^{-1}\right)$ & 8.7 & 8.0 \\
\hline N Kjeldahl (\%) & 1.8 & 1.7 \\
\hline $\mathrm{P}_{2} \mathrm{O}_{5}(\%)$ & 0.6 & 3.9 \\
\hline $\mathrm{K}_{2} \mathrm{O}(\%)$ & 1.2 & 0.8 \\
\hline $\mathrm{CaO}(\%)$ & 5.4 & 9.5 \\
\hline $\mathrm{MgO}(\%)$ & 0.4 & 1.2 \\
\hline $\mathrm{Na}(\%)$ & 0.6 & 0.0 \\
\hline $\mathrm{Fe}(\%)$ & 0.5 & 1.9 \\
\hline $\operatorname{Mn}\left(\mathrm{mg} \mathrm{kg}^{-1}\right)$ & 86 & 252 \\
\hline $\mathrm{Cu}\left(\mathrm{mg} \mathrm{kg}^{-1}\right)$ & 57 & 325 \\
\hline$Z n\left(\mathrm{mg} \mathrm{kg}^{-1}\right)$ & 49 & 563 \\
\hline $\mathrm{Pb}\left(\mathrm{mg} \mathrm{kg}^{-1}\right)$ & 60 & 184 \\
\hline $\mathrm{Ni}\left(\mathrm{mg} \mathrm{kg}^{-1}\right)$ & 16 & 59 \\
\hline $\mathrm{Cd}\left(\mathrm{mg} \mathrm{kg}^{-1}\right)$ & $<1$ & 2.0 \\
\hline C/N ratio & 44 & 13 \\
\hline Dissolved organic matter $\left(\mathrm{g} \mathrm{kg}^{-1}\right)$ & 0.7 & 0.1 \\
\hline Microbial content $\left(C F \cup g^{-1}\right)$. Specific diuron degraders & $23 \times 10^{5}$ & $68 \times 10^{5}$ \\
\hline Soluble phosphorous $\left(\mathrm{mg} \mathrm{L}^{-1}\right)$ & 90 & 17 \\
\hline Soluble nitrogen $\left(\mathrm{mg} \mathrm{L}^{-1}\right)$ & 670 & $60 \times 10^{3}$ \\
\hline
\end{tabular}

Table 2. First order kinetic parameters (Single First Order, SFO, or Hockey-Stick, HS, models) for mineralisation curves of diuron obtained after micronutrients (TES), cyclodextrin (HPBCD) and/or composts application (SS and USR) at different concentrations.

\begin{tabular}{|c|c|c|c|c|c|c|c|}
\hline Treatments & $\begin{array}{c}\text { Kinetic } \\
\text { model }\end{array}$ & $k_{1}\left(\right.$ day $\left.^{-1}\right)$ & $k_{2}\left(\operatorname{day}^{-1}\right)$ & $\begin{array}{c}\text { tb } \\
\left(\text { day }^{-1}\right)\end{array}$ & \begin{tabular}{|c|} 
Lag \\
phase \\
(days) \\
\end{tabular} & $\begin{array}{l}\mathrm{DT}_{50} \\
\text { (days) }\end{array}$ & $\begin{array}{c}\text { Extent of } \\
\text { mineralisation } \\
(\%)\end{array}$ \\
\hline Soil + TES & $H S$ & $5.1 \cdot 10^{-3}$ & $0.9 \cdot 10^{-4}$ & 68.0 & 39 & 6297 & 15.5 \\
\hline Soil + TEs + 0.5\% SS & SFO & $8.6 \cdot 10^{-4}$ & - & - & 60 & 804 & 13.9 \\
\hline Soil + TEs + 2\% SS & SFO & $2.0 \cdot 10^{-3}$ & - & - & 27 & 360 & 24.5 \\
\hline Soil + TES + 4\% SS & SFO & $3.0 \cdot 10^{-3}$ & - & - & 18 & 240 & 32.9 \\
\hline Soil + TEs + 0.5\% USR & SFO & $9.5 \cdot 10^{-4}$ & - & - & 54 & 734 & 13.4 \\
\hline Soil + TEs + 2\% USR & SFO & $1.2 \cdot 10^{-3}$ & - & - & 49 & 660 & 14.6 \\
\hline Soil + TEs + 4\% USR & SFO & $3.0 \cdot 10^{-3}$ & - & - & 18 & 244 & 33.1 \\
\hline Soil + TEs + HPBCD $\times 10$ & $H S$ & $2.6 \cdot 10^{-2}$ & $4.0 \cdot 10^{-4}$ & 42.2 & 33 & 1778 & 29.7 \\
\hline $\begin{array}{l}\text { Soil + TES + HPBCD } \times 10+4 \% \\
\text { SS }\end{array}$ & HS & $2.0 \cdot 10^{-2}$ & $3.0 \cdot 10^{-3}$ & 21.4 & 11 & 174 & 46.5 \\
\hline $\begin{array}{l}\text { Soil + TEs + HPBCD } \times 10+4 \% \\
\text { USR }\end{array}$ & HS & $2.5 \cdot 10^{-2}$ & $3.6 \cdot 10^{-4}$ & 40.2 & 16 & 1606 & 33.2 \\
\hline
\end{tabular}

